\title{
Efficacy of a Blended Learning Programme in Enhancing the Communication Skill Competence and Self-Efficacy of Nursing Students in Conducting Clinical Handovers: A Randomised Controlled Trial
}

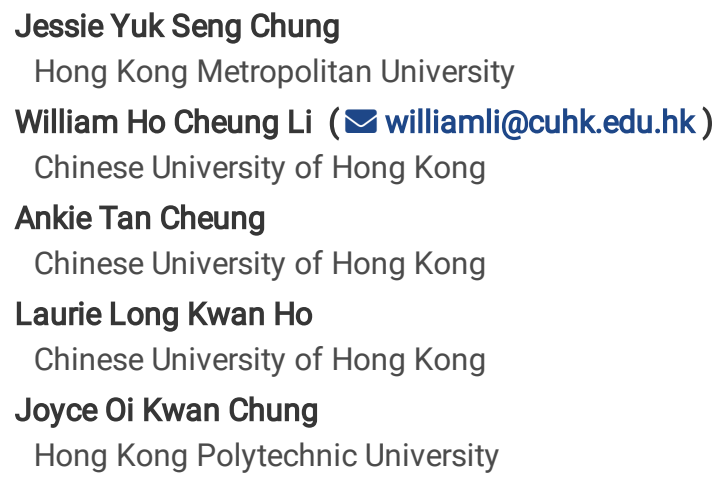

\section{Research Article}

Keywords: Blended learning, online module, clinical handover, communication skill competence, self-efficacy, nursing students Posted Date: January 31st, 2022

DOl: https://doi.org/10.21203/rs.3.rs-1215370/v1

License: (1) This work is licensed under a Creative Commons Attribution 4.0 International License. Read Full License 


\section{Abstract}

Background: A clinical handover is an essential nursing practice that ensures patient safety. However, most newly graduated nurses struggle to conduct clinical handovers as they lack sufficient communication skill competence and self-efficacy in this practice. This study aimed to examine the efficacy of a blended learning programme in enhancing the communication skill competence and self-efficacy of final-year nursing students in conducting clinical handovers.

Methods: A randomised controlled design was used. A convenience sample of 96 final-year baccalaureate nursing students at a local university, who had no previous training in clinical handovers. Data were collected in 2020. Participants were randomly assigned to either an experimental group $(n=50)$ that received a blended learning programme with face-to-face training and an online module on handover practice, or a waitlist control group $(n=46)$ that received only face-to-face handover training during the study period and an online module immediately after the completion of data collection. The outcomes were the communication skill competence and self-efficacy of the participants in conducting clinical handovers.

Results: We found that the participants in the experimental group had significantly higher communication skill competence $(p<0.001)$ than those in the waitlist control group. Although both groups showed a significant improvement in self-efficacy, the mean scores of the experimental group were higher than those of the waitlist control group $(p<0.001)$.

Conclusions: This study demonstrated the efficacy of a blended learning approach in improving the communication skill competence and self-efficacy of final-year nursing students in conducting clinical handovers. The findings have implications for the clinical handover training programme.

Trial registration: The study protocol was registered in the Registration ClinicalTrials.gov (NCT05150067; retrospective registration; date of registration 08/12/2021).

\section{Background}

A clinical handover is an essential nursing practice to ensure patient safety by conveying relevant patient care information and facilitating countinity of patient care from one healthcare provider to another [1,2]. To enable the provision of continuous patient care, the handover information must be clear, concise and systematic [3]. Communication and information that are unclear and unsystematic often impede the clarity of ideas, lead to the omission of important patient information and delay medical treatment, ultimately affecting patient safety [4-6]. Previous studies conducted in the United States, United Kingdom and Korea have shown that ineffective clinical handovers can impose huge financial burdens on the healthcare system [7-9].

A review of the literature revealed that nursing students and newly graduated nurses often struggle with clinical handovers due to a lack of communication skill competence and self-efficacy in performing this practice [10-12], especially delivering clinical handover, which is a source of frustration for the newly graduated nurses $[13,14]$. A recent qualitative study examined the experiences of newly graduated nurses in Hong Kong in performing clinical handovers and found that most of them perceived barriers to handover, such as inadequate professional judgement, poor ability to synthesise important information and unsystematic reporting [15]. Moreover, many of the nurses claimed in interviews that they were not adequately prepared for clinical handovers during their undergraduate course [15]. It is well documented that education and practice play essential roles in enhancing effective communication during handover [16, 17]. However, teaching clinical handover practice to nursing students is often overlooked and not given enough importance [15]. The current nursing curriculum in the local institutions also lack a well-structured and comprehensive training programme for teaching the communication skills required for efficient handover [15]. Therefore, a revision of the current nursing curriculum to include a customised clinical handover training programme that maximises the students' knowledge and skills in communication and thus builds their competence and self-efficacy is of paramount importance [18].

Blended learning programmes (BLPs) are commonly used as constructivist pedagogical approaches in nursing education [19]. They involve both face-to-face components and online engagement [20]. The online learning components are usually flexible, inexpensive and can be easily adapted to individual needs and completed at any time and location of choice. This allows learners to be in full control of the learning pace [21]. The online learning modules also provide multiple learning opportunities to the participants, which they can use to practice the skills they learn until they attain mastery. A recent study suggested that blended learning approaches can also solve the issue of large class [22] as it allows instructors to address a large number of learners at the same time and provide adequate opportunities for the learners to practice their skills. 
The use of BLPs has been proven successfully in nuring education in terms of teaching theoretical courses and psychomotor skills in nursing education, as well as enhancin the knowledge [23, 24], self-efficacy [23], motivation [25], attitudes [26] and perceived competence of students [27]. Despite this, no studies that examine the efficacy of BLPs in improving nursing students' communication skill competence and self-efficacy in conducting clinical handovers have been identified in PubMed, in the Cochrane Library or on clinical trial registries (ClinicalTrials.gov and ISRCTN). In this study, we aimed to test the efficacy of BLP in enhancing nursing students' communication skill competence and self-efficacy in performing clinical handovers.

\section{Theoretical framework}

The blended clinical handover training programme used in this study was guided by the self-efficacy theory [28]. Bandura defines selfefficacy as an individual's belief in his/her own abilities to achieve a certain level of performance in solving a difficult task. The theory identifies four sources of self-efficacy: mastery experiences, vicarious experiences, verbal persuasion and physiological arousal [28]. A direct experience of mastery is the most powerful means of increasing self-efficacy. Vicarious experiences are achieved by observing one's peers; observing successful peers helps students develop the belief that they too can succeed. Verbal persuasion, such as teacher feedback, encouragement and other external reinforcements, can positively strengthen one's self-efficacy. Physiological arousal can manifest as negative emotions such as anxiety, high levels of stress and self-doubt, which can negatively impact one's perception of self-efficacy.

An online module was incorporated in the blended clinical handover training programme. In this module, scenario-based exercises were introduced to allow students to make use of the learned clinical handover technique when conducting handover reporting (learning from their own experiences). The sharing of experiences on an online platform also allowed students to refer to the work of their peers (learning from one another). Students were encouraged to discuss their issues and experiences on the online forum to form and exchange their own opinions. After each exercise, the teacher provided individual feedback on the students' performances to meet the goals of verbal persuasion and physiological arousal, which helped identify the strengths and shortcomings of the students and deal with their negative emotions. All of the above will strengthen the students' self-efficacy and consequently enhance their competence in conducting clinical handovers.

\section{Methods}

\section{Study design and setting}

A single-centre, two-arm, parallel design randomised control trial (RCT) with a waitlist control group was conducted in a university between 4 May 2020 and 8 June 2020. The study strictly followed the Consolidated Standards of Reporting Trials (CONSORT) 2010 guidelines.

\section{Participants and sample size}

Convenience sampling was used to recruit final-year baccalaureate nursing students. They were eligible to participate if they: a) were Hong Kong residents who could speak Cantonese and read Chinese and English; b) were aged at least 18 years; and c) had not previously enrolled in a clinical handover training programme.

G*Power 3 was used to estimate the sample size [29]. Based on previous studies of online modules and peer-learning in handover training for healthcare professionals [30,31], the intervention effect size was determined to be 0.60 , which represented a moderate effect size [32]. To predict the differences between the two groups (two tails) with an effect size of 0.60 , a level of significance of $5 \%$ and power of 0.8 , a minimum sample size of 90 participants was required. Considering a potential retention rate of $95 \%$, at least 95 participants were required.

\section{Randomisation and concealment}

The participants were randomly assigned to either the intervention group or waitlist control group. Randomisation was performed by a research team member who opened a serially labelled, opaque, sealed envelope that contained a card indicating a randomly allocated group. The random numbers used for group assignment were generated before participant recruitment by another research team member using a personal computer. Allocation concealment was ensured.

\section{Interventions}

The training programme aimed to improve the communication skill competence and self-efficacy of nursing students in conducting clinical handovers. The content of the training programme was designed to match the learning needs of newly graduated nurses regarding clinical handover. Therefore, it covered the identification of key information for handover, synthesis of nursing assessments and important patient needs, and systematic handover reporting (Chung et al., 2021). Thus, a well-structured BLP for handover practice with a face-to-face training workshop and an online module was developed. 
The face-to-face training workshop aimed to provide knowledge of clinical handovers and introduce the Situation, Background, Assessment, Recommendation (SBAR) technique. The SBAR technique was included in the training workshop to ensure efficient communication among the nursing students $[25,26]$. It serves as a checklist for nursing communication and enhances their confidence when conversing with other healthcare professionals [25-27]. Previous studies have found that successful application of the SBAR technique could reduce patient risk [33] and increase patient and staff satisfaction in high-risk environments such as intensive care units, emergency rooms and operating rooms [34]

Within 2 weeks of completing the face-to-face training workshop, the participants in the experimental group were invited to access the online module. The online module aimed to provide ample practice to master the technique, sufficient opportunities to learn from the outstanding reports of their peers and thereby gain vicarious experiences, and enough constructive feedback on their performance to achieve verbal persuasion and physiological arousal.

The participants in the waitlist control group received the same face-to-face training workshop as the experimental group. However, these participants were invited to access the online module only after data collection was completed.

\section{Data collection}

After obtaining written informed consent, the participants' baseline characteristics, such as age, sex and previous experience of observing and performing clinical handovers, and their baseline self-efficacy levels in conducting clinical handovers were collected. The participants' levels of self-efficacy and communication skill competence in conducting clinical handovers were assessed 2 weeks after they received the intervention.

\section{Measures and instruments}

The primary outcome was the participants' communication skill competence in conducting clinical handovers, which was assessed using the SBAR Communication and Communication Clarity tool [35]. The assessment had 23 items that were rated on a Likert scale and had a Cronbach's a of 0.84 [35]. The SBAR Communication was used to examine students' skill performance of adopting SBAR technique in clinical handover and the Communication Clarity aimed to assess whether the participants are able to identify important information and transfer it accurately and understandably. Higher scores correspond to better performance. The tool was reviewed for content validity by an expert panel that consisted of clinical nurses and nursing faculty.

The case scenario developed for skill assessment was reviewed by the expert panel and finalised after multiple reviews and modifications. The expert panel commented that the content and level of difficulty of the case scenario were appropriate for the assessment of communication skill competence. The participants were requested to conduct a clinical handover based on the case scenario, audio record the report and submit it to the online module. All of the handover reports were audio recorded anonymously and saved using an assigned number code to reduce impression-induced biases. The assessor was blinded to the group assignment so that the scores remained unbiased. To enhance the reliability of the assessment and reduce the discrepancy in ratings, we used only a single assessor [36].

The participants' self-perceived communication self-efficacy level in conducting clinical handovers was assessed using a visual analogue scale (VAS). The VAS values were found to reliably reflect the participants' true attitudes with low distortion and bias [37]. The validity of the VAS as a measure of self-efficacy has also been proven by Turner, van de Leemput, Draaisma, Oosterveld and ten Cate [38]. It has been adopted by various studies to assess the self-efficacy and communication skills of nursing students [39] and the level of confidence of nurses in the truth of the information transmitted during handover [40].

The participants were requested to drag a sliding bar from 0 to 100 on the online survey platform to indicate the level of confidence in their ability to conduct clinical handovers $(0=$ Not at all confident, $100=$ Extremely confident $)$.

\section{Data analysis}

Data analysis was performed using SPSS for Windows v26.0 (IBM Corp, 2019). Descriptive statistics were used to calculate the mean scores and standard deviations for each scale. The baseline characteristics and research outcomes were compared between the groups using independent samples $t$-test for parametric variables, chi-squared and Fisher's exact tests for categorical variables and Mann-Whitney $U$ test for continuous variables. The Pearson correlation test and Spearman's correlation were used to analyse the inter-variable correlations. An analysis of covariance (ANCOVA) was used to examine the between-subjects effects on self-efficacy and communication skill competence in conducting clinical handovers after controlling for the significantly correlated variables. A paired sample $t$-test was used to determine the within-subjects effects on self-efficacy. 


\section{Ethical considerations}

This study was approved by the Institutional Review Board of the University of Hong Kong (reference, UW 19-622). An electronic poster with information about the study was sent to the target population. Interested nursing students could contact the study team for enrolment. Nursing students were told that their participation was entirely voluntary and that they had the right to withdraw from the study at any point of time. They were also assured of the confidentiality of their data. An information sheet was provided to all of the participants and written consent was obtained.

\section{Results}

\section{Recruitment and randomisation}

We approached and assessed 178 final-year nursing students from the academic year of 2019 for eligibility. Ninety-six students were enrolled in the study and randomly assigned to either the experimental group or the waitlist control group. Two students in the experimental group and five students in the control group were unable to complete the skill assessment due to physical illnesses. Finally, 89 students completed the study (experimental group: $n=48$; control group: $n=41$ ) (Figure 1).

\section{Baseline characteristics of the participants}

Table 1 outlines the baseline characteristics of both groups. All of the participants were Chinese, and most of them were female $(n=82$, $85.4 \%$ ). The mean ages of the participants in the experimental group and control group were 23.5 years and 23.4 years, respectively. There were no statistically significant differences in the demographic or baseline data between those who completed the study and those who dropped out, and between the experimental and control groups.

\section{Within-subjects effects}

Table 2 shows the mean self-efficacy scores of both groups at baseline and after the intervention. We found a statistically significant improvement in the self-efficacy scores of both groups at 2 weeks after the intervention, regardless of the intervention received.

\section{Inter-variable correlation matrix}

The correlation matrix is presented in Table 3. The participants' previous experience of observing and performing clinical handovers was significantly correlated with baseline self-efficacy, but not with post-intervention self-efficacy. However, the latter was significantly and positively correlated with communication skill competence. The participants who had higher post-intervention self-efficacy in conducting clinical handovers also performed better in the communication skill competence assessment.

\section{Between-subjects effects}

The communication skill competence assessment scores and self-perceived self-efficacy in conducting clinical handovers of the participants from both groups are presented in Table 4. The baseline and post-intervention self-efficacy were considered as covariates because they were significantly correlated with the post-intervention self-efficacy and communication skill competence, respectively. The participants in the experimental group reported significantly higher mean scores in the skill competence assessment than those in the waitlist control group; $(F 1,87)=123.49, \mathrm{p}<.001, \mathrm{~h}^{2}=.59$.

The mean self-efficacy scores were significantly higher in the experimental group than in the waitlist control group after controlling for the mean self-efficacy scores on the pretest; $(F 1,86)=20.83, p<.001, h^{2}=.20$.

\section{Discussion}

Communication skills and self-efficacy are essential components of handing over the responsibility of patient care to other healthcare professionals. To the best of our knowledge, this is the first RCT to evaluate the efficacy of a BLP in enhancing the communication skill competence and self-efficacy of nursing students in conducting clinical handovers. The overall results demonstrate the efficacy of the proposed intervention in enhancing the clinical handover practice of nursing students.

The results showed that the students' previous experience of observing and performing clinical handovers was correlated with baseline selfefficacy, but not post-intervention self-efficacy. Moreover, the post-intervention self-efficacy scores were higher for the experimental group than for the waitlist control group. These findings indicated that although previous experience of clinical handover practice was important, the BLP had a more impactful role in enhancing the students' self-efficacy. The participants in both groups also showed a significant 
improvement in self-efficacy, with the experimental group showing a markedly higher improvement. In the current Hong Kong nursing curriculum, a face-to-face training workshop is the most common teaching strategy used to prepare nursing students for clinical handover. Nevertheless, there is room for improvement in this strategy. This study demonstrates that the students' self-efficacy was further enhanced by the addition of an online module to the existing face-to-face training workshop. Most importantly, students who received blended clinical handover training achieved significantly higher mean scores in communication skill competence assessments than those who received only a face-to-face training workshop. These findings demonstrate the importance of incorporating a blended learning approach in the curriculum; thus, a combination of a face-to-face training workshop with an online module can efficiently teach nursing students about clinical handovers [41]. The online module with scenario-based exercises encouraged the students to make use of the SBAR technique when conducting clinical handovers and provided more opportunities for them to practice these skills, which consequently improved their selfefficacy [42] and communication skill competence [43]. These findings were consistent with previous studies conducted on medical interns and postgraduate residents that demonstrated the efficacy of using online modules to improve their self-efficacy in conducting clinical handovers $[31,44]$.

\section{Limitations}

This study had some limitations. First, the students who chose to participate might have had higher motivation and willingness to learn the skill, making the intervention more effective for them. Second, the outcomes were measured at the baseline and immediately postintervention, leaving the long-term effects of the intervention unknown. Third, the study was conducted in a single centre, limiting the generalisability of its findings. Finally, the SBAR communication tool was used to measure the communication skill competence, which aimed to examine the students' skill performance in adopting the SBAR technique for clinical handovers. This implied that the communication skill competence was not assessed at the beginning of the study as the students had not learned the technique by then. In future studies, pretest data on communication skill competence should be collected immediately after the face-to-face training workshop. Conducting the pretest after the training workshop is an alternative way of collecting data as all of the participants would by then have the basic knowledge and skills required to adopt the SBAR technique for clinical handovers. Comparing their performances after the face-to-face training workshop and after the experimental group completes the online learning will help determine whether the online module has an additional effect on the communication skill competence of the participants in the experimental group.

\section{Implications}

The results of this study suggest a need for more training for undergraduate nursing students. The acquisition of knowledge and ample practice of skills will raise their self-efficacy and improve their skill competence. To achieve this goal, a blended learning approach can be used to teach nursing students about clinical handovers. A BLP provides plenty of learning opportunities in a flexible manner for students to practice their skills. Using a blended learning approach for clinical handovers is an innovative teaching strategy that can improve the skill competence of nursing students, enhance the quality of nursing care and promote patient safety [45]. Moreover, the online component of the training programme is particularly advantageous during pandemics, when face-to-face teaching is not feasible. It allows students to learn in safe environments while practicing social distancing. In addition, the communication skill competence assessment conducted in this study was developed based on the Objective Structured Clinical Examination (OSCE). The results of this study demonstrate the utility of the OSCE, which can be incorporated in future studies to objectively assess the actual performance of the participants' handover reporting skills. Most importantly, the results of this study can be used to optimise the content of training programmes for clinical handover in the nursing curriculum.

\section{Conclusion}

This study supports the efficacy of using a BLP to enhance the communication skill competence and self-efficacy of nursing students in conducting clinical handovers. A well-structured and comprehensive clinical handover training programme must be incorporated into the nursing curriculum with the aim of preparing nursing students for their future roles and responsibilities after graduation.

\section{Declarations}

\section{Ethics approval and consent to participate}

Before data collection, the study has sought ethical approval from the Institutional Review Board (IRB) of the University of Hong Kong was obtained in September 2019 (reference, UW 19-622), and the Open University of Hong Kong was obtained in October 2019. All participants were fully informed about the aim and procedure of this study. An information sheet had been provided to all participants, and written consent had been obtained. Voluntary participation was strongly highlighted to the students, and choosing not to participate in this study 
will not harm their grades and learning journey. Ample time was given to the students to seek clarifications and pose questions. All methods were carried out in accordance with relevant guidelines and regulations.

\section{Consent for publication}

Not applicable

\section{Availability of data and materials}

The datasets generated and/or analysed during the current study are not publicly available due to privacy and ethical issue but are available from the corresponding author on reasonable request.

\section{Competing interests}

The author(s) declare(s) that they have no competing interests.

\section{Funding}

This work was supported by a N\&HS Mini Grant for Research Projects (grant number HE12September2018-N\&HS2014/01) from the Hong Kong Metropolitan University.

\section{Authors' contributions}

JYSC, WHCL and JOKC had full access to all of the data in the study and take responsibility for the integrity of the data and the accuracy of the data analysis. JYSC, WHCL, ATC, LLKH, and JOKC searched the literature, reviewed the literature and extracted data. JYSC, WHCL and JOKC completed the statistical analysis. JYSC, WHCL and JOKC drafted the manuscript. All authors have contributed to the critical revision of the manuscript for important intellectual content. The study was under the supervision of WHCL. The corresponding author attests that all listed authors meet authorship criteria and that no others meeting the criteria have been omitted.

\section{Acknowledgements}

We would like to acknowledge and express our gratitude to the nurses and students who participated so willingly in this study. Their heartfelt sharing, time, commitment, and interest in this research made the study possible.

Our sincere thanks are also given to the nurse educators, nurses, and research assistants for their co-operation, support, and friendliness during the intervention development and data collection period. Besides, we would like to express my gratitude to the former Dean of the School of Nursing and Health Studies, Prof Joseph Lee Kok Long and the Associate Dean, Prof Linda Lee Yin King of this project's research institute, and those who facilitated access to the associated research sites.

\section{References}

1. Phillippe SS. Care Coordination and Handoff for the Pediatric Patient in the Radiology Environment. J Radiol Nurs. $2017 ; 36(1), 59-62$. doi:10.1016/j.jradnu.2017.01.002

2. Johnson M, Jefferies D, Nicholls D. Exploring the structure and organization of information within nursing clinical handovers. Int $J$ Nurs Pract. 2012;18(5):462-470. doi:10.1111/j.1440-172X.2012.02059.x

3. Birmingham P, Buffum MD, Blegen MA, Lyndon A. Handoffs and Patient Safety: Grasping the Story and Painting a Full Picture. West J Nurs Res. 2015;37(11):1458-1478. doi:10.1177/0193945914539052

4. Arora VM, Eastment MC, Bethea ED, Farnan JM, Friedman ES. Participation and experience of third-year medical students in handoffs: time to sign out?. J Gen Intern Med. 2013;28(8):994-998. doi:10.1007/s11606-012-2297-9

5. Horwitz LI, Moin T, Krumholz HM, Wang L, Bradley EH. Consequences of inadequate sign-out for patient care. Arch Intern Med. 2008;168(16):1755-1760. doi:10.1001/archinte.168.16.1755

6. Saleem AM, Paulus JK, Vassiliou MC, Parsons SK. Initial assessment of patient handoff in accredited general surgery residency programs in the United States and Canada: a cross-sectional survey. Can J Surg. 2015;58(4):269-277. doi:10.1503/cjs.016414

7. Kern, C. Healthcare Miscommunication Costs 2,000 Lives and \$1.7 Bilion. Health IT Outcomes. 2016. https://www.healthitoutcomes.com/doc/healthcare-miscommunication-costs-lives-and-billion-0001 . Accessed 11 Feb 2016.

8. Park SH, Lee TW. Predicting patient safety behaviors of nurses in inter-hospital transfer. J Korean Acad Nurs Adm. 2016;22(3):230-238. doi:10.11111/jkana.2016.22.3.230

Page $7 / 12$ 
9. Sujan M, Spurgeon P, Inada-Kim M, et al. Clinical handover within the emergency care pathway and the potential risks of clinical handover failure (ECHO): primary research. Southampton (UK): NIHR Journals Library; March 2014.

10. Duong JA, Jensen TP, Morduchowicz S, Mourad M, Harrison JD, Ranji SR. Exploring Physician Perspectives of Residency Holdover Handoffs: A Qualitative Study to Understand an Increasingly Important Type of Handoff. J Gen Intern Med. 2017;32(6):654-659. doi:10.1007/s11606-017-4009-y

11. Lavoie P, Clausen C, Purden M, Emed J, Frunchak V, Clarke SP. Nurses' experience of handoffs on four Canadian medical and surgical units: A shared accountability for knowing and safeguarding the patient. J Adv Nurs. 2021;77(10):4156-4169. doi:10.1111/jan.14997

12. Sabet Sarvestani R, Moattari M, Nasrabadi AN, Momennasab M, Yektatalab S. Challenges of nursing handover: a qualitative study. Clin Nurs Res. 2015;24(3):234-252. doi:10.1177/1054773813508134

13. Ascano-Martin F. Shift report and SBAR: strategies for clinical postconference. Nurse Educ. 2008;33(5):190-191. doi:10.1097/01.NNE.0000334779.90395.67

14. Tschannen D, Aebersold M, McLaughlin E, Bowen J, Fairchild J. Use of virtual simulations for improving knowledge transfer among baccalaureate nursing students. J Nurs Educ Pract. 2012;2. doi:10.5430/jnep.v2n3p15

15. Chung JYS, Li WHC, Ho LLK, Cheung AT, Chung JOK. Newly graduate nurse perception and experience of clinical handover. Nurse Educ Today. 2021;97:104693. doi:10.1016/j.nedt.2020.104693

16. Kicken W, Van der Klink M, Barach P, Boshuizen HP. Handover training: does one size fit all? The merits of mass customisation. BMJ Qual Saf. 2012;21 Suppl 1:i84-i88. doi:10.1136/bmjqs-2012-001164

17. Weissman GV. Evaluating associate degree nursing students' self-efficacy in communication skills and attitudes in caring for the dying patient. Teaching and Learning in Nursing. 2011;6(2):64-72. doi:10.1016/j.teln.2010.10.004

18. O' Byrne WI, Pytash KE. Hybrid and Blended Learning. J Adolesc Adult Lit. 2015;59(2):137-140. doi:10.1002/jaal.463

19. Moon H, Hyun HS. Nursing students' knowledge, attitude, self-efficacy in blended learning of cardiopulmonary resuscitation: a randomized controlled trial. BMC Med Educ. 2019;19(1):414. Published 2019 Nov 9. doi:10.1186/s12909-019-1848-8

20. Tan AJQ, Lee CCS, Lin PY, et al. Designing and evaluating the effectiveness of a serious game for safe administration of blood transfusion: A randomized controlled trial. Nurse Educ Today. 2017;55:38-44. doi:10.1016/j.nedt.2017.04.027

21. Choi SH, Kim YH. Effects of Smoking Cessation Intervention Education Program Based on Blended Learning among Nursing Students in South Korea. Osong Public Health Res Perspect. 2018;9(4):185-191. doi:10.24171/j.phrp.2018.9.4.07

22. McCutcheon K, O'Halloran P, Lohan M. Online learning versus blended learning of clinical supervisee skills with pre-registration nursing students: A randomised controlled trial. Int J Nurs Stud. 2018;82:30-39. doi:10.1016/j.ijnurstu.2018.02.005

23. Jang HJ, Hong SY. Effect of Blended Learning in Nursing Education. Int J Multimedia Ubiquitous Eng. 2016;11(5):297-304.

24. Park JY, Woo CH, Yoo JY. Effects of Blended Cardiopulmonary Resuscitation and Defibrillation E-learning on Nursing Students' Selfefficacy, Problem Solving, and Psychomotor Skills. Comput Inform Nurs. 2016;34(6):272-280. doi:10.1097/CIN.0000000000000227

25. Dunsford J. Structured communication: improving patient safety with SBAR. Nurs Womens Health. 2009;13(5):384-390. doi:10.1111/j.1751-486X.2009.01456.x

26. Street M, Eustace P, Livingston P, Craike M, Kent B, Patterson D. Communication at the bedside to enhance patient care: A survey of nurses' experience and perspective of handover. Int J Nurs Pract. 2011;17(2):133. doi:10.1111/j.1440-172X.2011.01918.x

27. Compton J, Copeland K, Flanders S, et al. Implementing SBAR across a large multihospital health system. Jt Comm J Qual Patient Saf. 2012;38(6):261-268. doi:10.1016/s1553-7250(12)38033-1

28. Bandura A. Self-efficacy: toward a unifying theory of behavioral change. Psychol Rev. 1977;84(2):191-215. doi:10.1037//0033295x.84.2.191

29. Erdfelder FF, Buchner EA. Power Analysis for Categorical Methods. 2005. (pp. 1565-1570).

30. Kim JH, Hur MH, Kim HY. The efficacy of simulation-based and peer-learning handover training for new graduate nurses. Nurse Educ Today. 2018;69:14-19. doi:10.1016/j.nedt.2018.06.023

31. Thaeter L, Schröder H, Henze L, et al. Handover training for medical students: a controlled educational trial of a pilot curriculum in Germany. BMJ Open. 2018;8(9):e021202. Published 2018 Sep 12. doi:10.1136/bmjopen-2017-021202

32. Cohen J. A Power Primer. Psychol Bull. 1992;112(1):155-159. doi:10.1037/0033-2909.112.1.155

33. Amato-Vealey EJ, Barba MP, Vealey RJ. Hand-off communication: a requisite for perioperative patient safety. AORN J. 2008;88(5):763774. doi:10.1016/j.aorn.2008.07.022

34. Leonard M, Graham S, Bonacum D. The human factor: the critical importance of effective teamwork and communication in providing safe care. Qual Saf Health Care. 2004;13 Suppl 1(Suppl 1):i85-i90. doi:10.1136/qhc.13.suppl_1.i85

Page $8 / 12$ 
35. Yu M, Kang KJ. Effectiveness of a role-play simulation program involving the sbar technique: A quasi-experimental study. Nurse Educ Today. 2017;53:41-47. doi:10.1016/j.nedt.2017.04.002

36. Aarons GA, Ehrhart MG, Farahnak LR, Sklar M, Horowitz J. Discrepancies in Leader and Follower Ratings of Transformational Leadership: Relationship with Organizational Culture in Mental Health. Adm Policy Ment Health. 2017;44(4):480-491. doi:10.1007/s10488-015-0672-7

37. Klimek L, Bergmann KC, Biedermann T, et al. Visual analogue scales (VAS): Measuring instruments for the documentation of symptoms and therapy monitoring in cases of allergic rhinitis in everyday health care: Position Paper of the German Society of Allergology (AeDA) and the German Society of Allergy and Clinical Immunology (DGAKI), ENT Section, in collaboration with the working group on Clinical Immunology, Allergology and Environmental Medicine of the German Society of Otorhinolaryngology, Head and Neck Surgery (DGHNOKHC). Allergo J Int. 2017;26(1):16-24. doi:10.1007/s40629-016-0006-7

38. Turner NM, van de Leemput AJ, Draaisma JM, Oosterveld P, ten Cate OT. Validity of the visual analogue scale as an instrument to measure self-efficacy in resuscitation skills. Med Educ. 2008;42(5):503-511. doi:10.1111/j.1365-2923.2007.02950.x

39. Espinoza KE. Self-Efficacy in Situation Background Assessment and Recommendation Communication Using Information Technology in Baccalaureate Nursing. (Doctor of Philosophy), 2016. University of Nevada, Las Vegas.

40. Lee H, Cumin D, Devcich DA, Boyd M. Expressing concern and writing it down: an experimental study investigating transfer of information at nursing handover. J Adv Nurs. 2015;71(1):160-168. doi:10.1111/jan.12484

41. Radtke JV, Tate JA, Happ MB. Nurses' perceptions of communication training in the ICU. Intensive Crit Care Nurs. 2012;28(1):16-25. doi:10.1016/j.iccn.2011.11.005

42. Noh YG, Lee I. Effects of a stepwise handovers ISBARQ programme among nursing college students. Nurs Open. 2020;7(5):1551-1559. Published 2020 Jun 25. doi:10.1002/nop2.537

43. Jeong CY, Seo YS. Effect of the convergence communication training program for communication self-efficacy, communicative competence and interpersonal relations of nursing students. J Digit Converg. 2017;15(5):271-280. doi:10.14400/JDC.2017.15.5.271

44. Gaffney S, Farnan JM, Hirsch K, McGinty M, Arora VM. The Modified, Multi-patient Observed Simulated Handoff Experience (M-OSHE): Assessment and Feedback for Entering Residents on Handoff Performance. J Gen Intern Med. 2016;31(4):438-441. doi:10.1007/s11606-016-3591-8

45. Drach-Zahavy A, Hadid N. Nursing handovers as resilient points of care: linking handover strategies to treatment errors in the patient care in the following shift. J Adv Nurs. 2015;71(5):1135-1145. doi:10.1111/jan.1

\section{Tables}

Table 1. Comparison of the demographic and baseline characteristics between the participants who completed and dropped out of the study in each group, and between participants in experimental and control groups

${ }^{\wedge}$ Fisher's Exact test

+ Chi Square test

* Mann-Whitney U test.

\# Independent samples $t$-test

Statistical significance was determined at $\mathrm{p}$ value $<0.05$.

$\mathrm{CH}=$ clinical handover

Table 2. Within-Subjects Effects of the Clinical Handover Training Course on the Self-Efficacy 


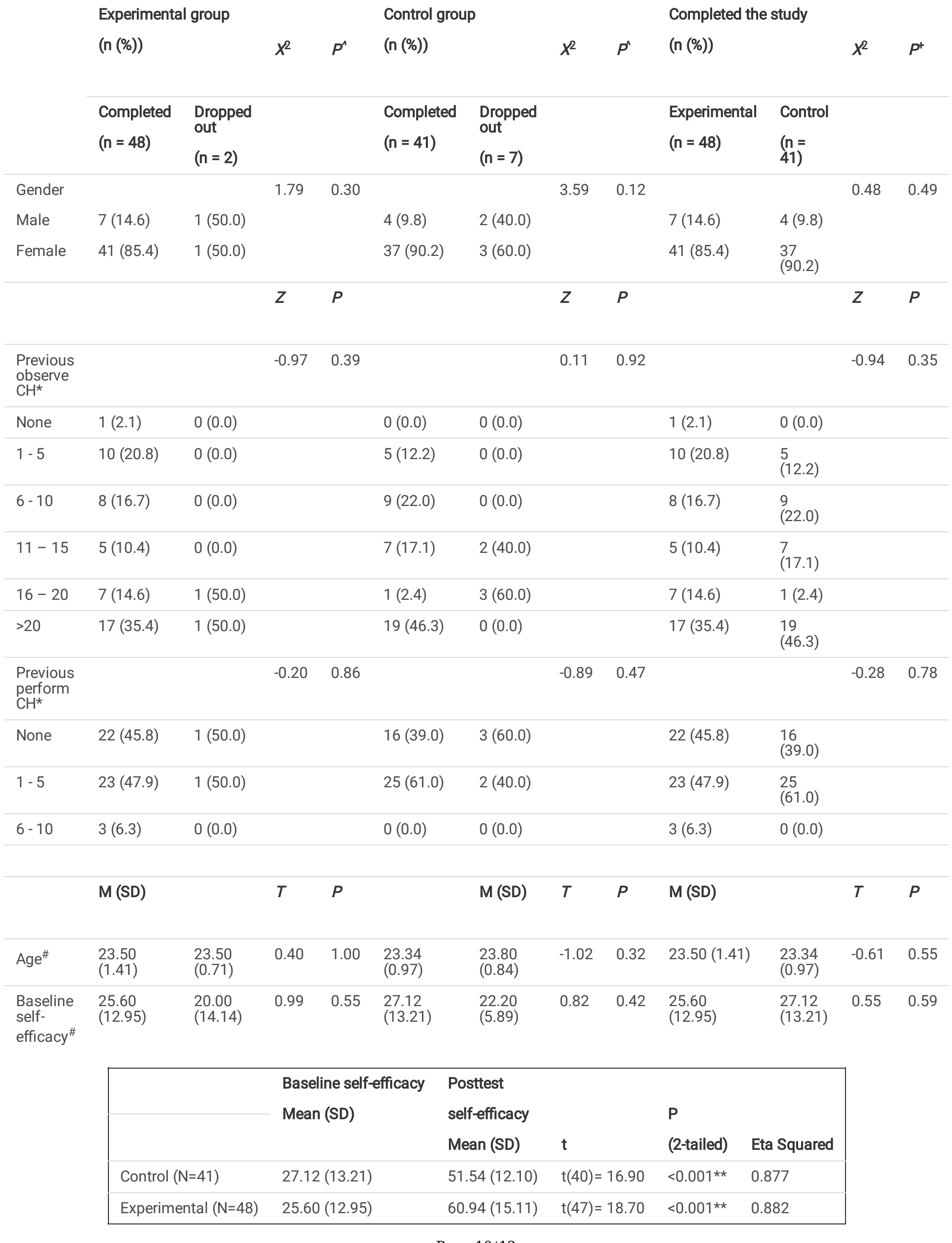


Effect size (eta squared) conventions: small effect $=0.01$; moderate effect $=0.06$; large effect $=0.14$.

**significant result as $p<0.001$.

Table 3. Inter-variable correlation matrix - Pearson's correlation test

\begin{tabular}{|llllll|}
\hline & Observe $\mathrm{CH}^{\#}$ & Perform CH$^{\#}$ & Baseline SE & Post SE & OSCE \\
\hline & Correlation coefficient $(\boldsymbol{p})$ & & & \\
\hline Previous observe $\mathrm{CH}^{\#}$ & 1 & $0.21\left(0.04^{*}\right)$ & $0.34\left(0.00^{\star *}\right)$ & $0.12(0.25)$ & $-0.15(0.18)$ \\
\hline Previous perform $\mathrm{CH}^{\#}$ & 1 & $0.38\left(0.00^{\star *}\right)$ & $0.02(0.89)$ & $0.03(0.76)$ \\
\hline Baseline SE & & 1 & $0.58\left(0.00^{\star *}\right)$ & $-0.10(0.37)$ \\
\hline Post SE & & & 1 & $0.21\left(0.04^{\star}\right)$ \\
OSCE & & & & 1 \\
\hline
\end{tabular}

\# Experience of observing clinical handover and performing clinical handover were assessed using nonparametric correlations - Spearmen's rho.

$\mathrm{CH}=$ clinical handover; SE = self-efficacy; OSCE = skill competence scores

*significant result as $p$-value $<0.05, * \star p<0.001$.

Table 4. Between-Subjects Effects of the Clinical Handover Training Course on the Communication Skill Competence and Self-Efficacy at two weeks after the intervention $(\mathrm{N}=89)$

\begin{tabular}{|c|c|c|c|c|c|c|c|}
\hline & & Control & Experimental $(n=48)$ & ANCOVA & & & \\
\hline DV & cov & $M(S D)$ & $M(S D)$ & F-value & $\mathbf{P}$ & Partial $\eta^{2}$ & Power \\
\hline OSCE & Post SE & $31.00(4.99)$ & $46.02(7.32)$ & $F(1,86)=113.18$ & $<0.001^{\star *}$ & 0.568 & 1.00 \\
\hline Post SE & Baseline SE & $51.54(12.10)$ & $60.94(15.11)$ & $F(1,86)=20.83$ & $<0.001^{* *}$ & 0.195 & 0.995 \\
\hline
\end{tabular}

Note. DV = dependent variable; $\mathrm{COV}$ = covariate; $\mathrm{OSCE}$ = skill competence scores; $\mathrm{SE}$ = self-efficacy

Effect size (eta squared) conventions: small effect $=0.01$; moderate effect $=0.06$; large effect $=0.14$.

**Significant at $p<0.05$.

\section{Figures}




\section{CONSORT}

TRANSPARENT REPORTING of TRIALS

\section{CONSORT 2010 Flow Diagram}

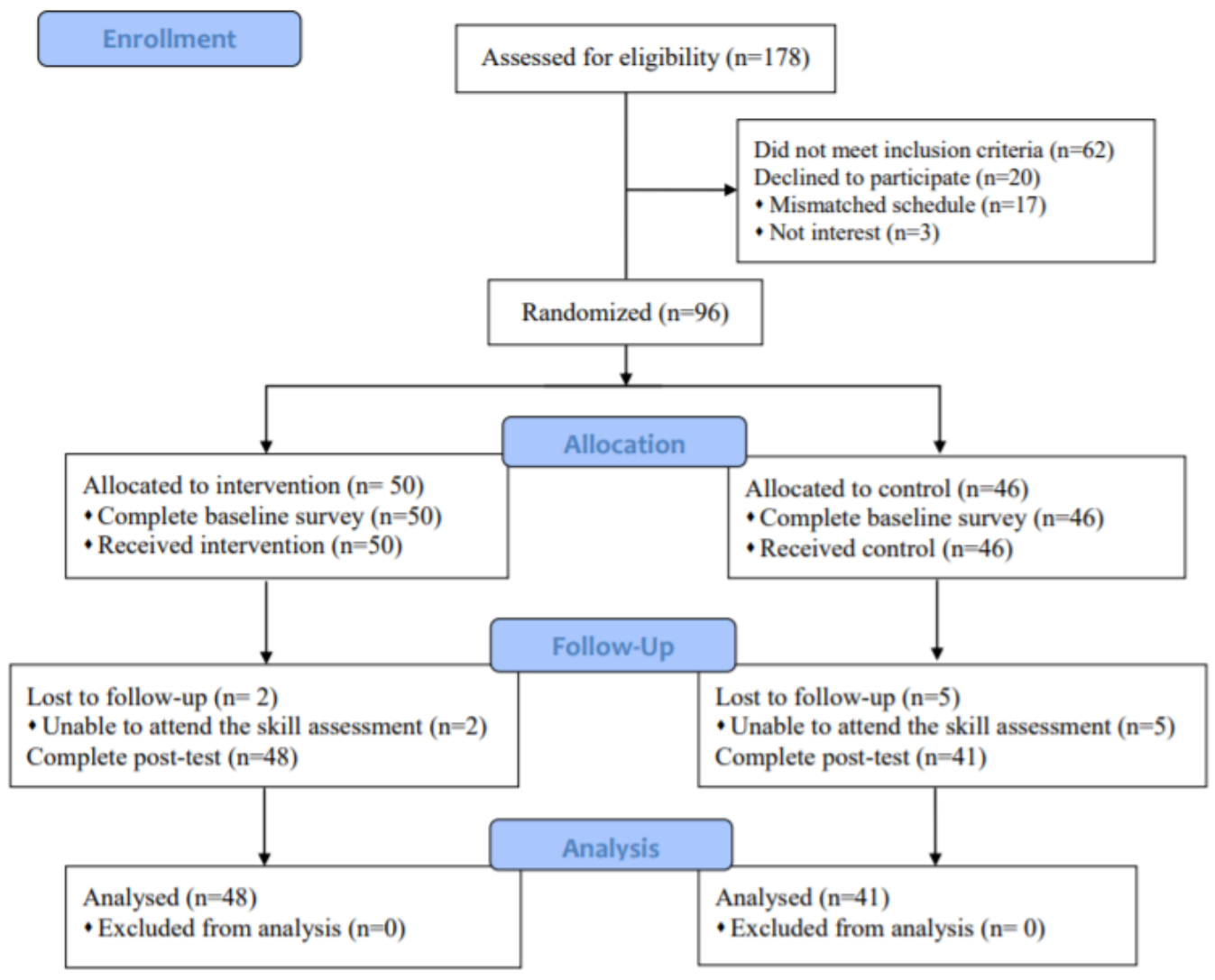

\section{Figure 1}

Participant flow from recruitment to postintervention follow-up. 